Introduction Musculoskeletal disorders (MSD) are of great concern among miners in Democratic Republic of Congo. This study sought to determine the prevalence of musculoskeletal disorders and associated factors among Namoya Mining workers who attended the company clinic between January 2015 and December 2016.

Method The study utilised company clinic data to find out the prevalence of MSDs among mine workers who attended mine's primary care clinic. Diagnoses of musculoskeletal disorders for the two year period were noted. Among those who had MSDs, other recorded data was extracted which included age, type of work, type of MSD, and management offered.

Results There were a total of 9753 clinic visits for the 2 year period of which MSDs accounted for 15.5\%. In 2015, 877 (18.47\%) MSD diagnoses were made of a total of 4747 who visited the clinic and 685 (13.6\%) MSDs noted of 5006 clinic visits in 2016. Back pain was the most common contributing 82.2\% of all MSDs while Work-Related Upper Limb Disorders (WRULDs) accounted for $8 \%$. The most affected were aged $30-40,78 \%$ and majority were shovel handlers (56\%) and mining operators/drivers (42\%). Over the 2 year period 1600 lumbar belts were issued and 7 surgical interventions done (discectomy) and over 10,000 $100 \mathrm{mg}$ of diclofenac sodium tablets prescribed

Discussion The estimated prevalence of MSDs at $15.5 \%$ is high compared to data from USA which was $5 \%$ before technological advancements (1983-1984) and 4\% after technological advancement (2003-2004). This might be attributed to the intensity of work. The management of MSDs can increase expenditure on medical and orthopaedic supplies and therefore need for preventive measures. Due to limited information recorded a comprehensive study is recommended to establish other related factors.

\section{PREVALENCE AND RISK FACTORS CORRELATED WITH OCCUPATIONAL BACK PAIN AMONG WORKERS IN ELECTRONIC INDUSTRY}

\footnotetext{
${ }^{1} \mathrm{P}$ Suggaravetsiri*, ${ }^{2,3} \mathrm{~S}$ Chaiklieng*. 'Department of Epidemiology and Biostatistics, Faculty of Public Health, Khon Kaen University, Thailand; '2Department of Environmental Health, Occupational Health and Safety, Faculty of Public Health, Khon Kaen University, Khon Kaen, Thailand; ${ }^{3}$ Research Centre in Back, Neck, Other Joint Pain and Human Performance (BNOJPH), Khon Kaen University
}

\subsection{6/oemed-2018-ICOHabstracts.722}

Introduction Persistent back pain is common in society and is clearly an occupation-related problem. The symptoms are prevalent among industrial workers involved sedentary work with prolonged sitting and occasional standing. The nature of industrially electronic work is repetitive and sedentary work which might increase back pain risk. This cross-sectional study aimed to identify the risk factors correlated with back pain among electronic workers at northeast, Thailand.

Methods There were 354 workers selected by simple random sampling from the electronic process of industry. Data were collected by an interview with the structural questionnaires, observation for ergonomics risk assessment with the standard tools of RULA and occupational stress test. Risk factors were identified by multiple logistic regressions with adjusted odd ratio $\left(\mathrm{OR}_{\mathrm{adj}}\right)$ and $95 \%$ confidence interval at $\mathrm{p}$-value $<0.05$.
Results The result showed that most workers were operator (92.09\%), age was 20-29 years old (63.84\%). Almost workers had work experience less than 5 years $(75.71 \%)$ and repetitive work $(83.62 \%)$. The highest risk from RULA found in workers had alternative sitting and standing/walking posture over shift work (68.49\%) and also in the group of machine controlled and changing material (71.70\%). The prevalence of back pain was $20.62 \%$ (95\% CI: 16.38 to 24.86 ) which was the highest prevalence among other areas. Risk factors significantly correlated with occupational back pain were low decision making $\left(\mathrm{OR}_{\mathrm{adj}}=2.26\right.$; 95\% CI: 1.26 to 4.05$)$, no exercise $\left(\mathrm{OR}_{\mathrm{adj}}=8.30 ; 95 \% \mathrm{CI}: 1.35\right.$ to 24.28$)$, overtime work $\left(\mathrm{OR}_{\mathrm{adj}}=3.39\right.$; $95 \% \mathrm{CI}: 1.16$ to 9.88$)$, repetitive posture $\left(\mathrm{OR}_{\mathrm{adj}}=2.94 ; 95 \% \mathrm{CI}: 1.19\right.$ to 7.29$)$ and very high ergonomics risk assessed by RULA $\left(\mathrm{OR}_{\mathrm{adj}}=2.48 ; 95 \% \mathrm{CI}\right.$ : 1.20 to 6.60; p-value $=0.018)$.

Conclusion This study indicated that the high ergonomics risk at machine controlled station and alternative sitting and standing stations must be implemented change soon. Work rotation management is suggested to provide in the working process. Repetitive work, low decision, and long overtime work should be considered for safety management in order to prevent back pain among electronic workers.

\section{CERVICAL PAIN IN TOBACCO FARMERS IN SOUTHERN BRAZIL}

${ }^{1}$ Anaclaudia Gastal Fassa*, 'Maitê Peres de Carvalho, ${ }^{1}$ Neice Muller Xavier Faria, ${ }^{2}$ Rodrigo Dalke Meucci, ${ }^{1}$ Nadia Spada Fiori. ${ }^{1}$ Federal University of Pelotas, Pelotas, Rio Grande do Sul, Brazil, ${ }^{2}$ Foundation Federal University of Rio Grande, Rio Grande, Rio Grande do Sul, Brazil

\subsection{6/oemed-2018-ICOHabstracts.723}

Introduction More than 200000 families are included in tobacco farming in Brazil. In harvesting, baling, cutting wood among other activities the farmers are exposed to vicious position, physical effort, repetitive movements and vibrations. Thus, this study evaluated the prevalence and factors associated with cervical pain in tobacco farmers in southern Brazil.

Methods A cross-sectional study was carried out with a representative sample of 2469 tobacco farmers from the municipality of São Lourenço do Sul/RS/Brazil. Cervical pain was characterised by an adaptation of the Nordic Questionnaire for Musculoskeletal Symptoms. The multivariate analysis was performed by Poisson regression, following a hierarchical model.

Results The prevalence of cervical pain in the last year was $7.4 \%, 9.1 \%$ for women and 6.2\% for men. Work at intense or accelerated pace and green tobacco sickness in the last year were positively associated with cervical pain in both sexes. However, smoking and baling were risk factors among women, while older age, using heavy chainsaw and having suffered pesticide poisoning showed a risk among men.

Conclusion The prevalence of cervical pain is similar to that found in other studies in farmers, but risk activities are marked by the sexual division of labour and are related to ergonomic exposures. The study points to the need to deepen understanding about the role of nicotine exposure in musculoskeletal problems. The mechanisation of the harvest and the activities needed to heal the leaf could reduce cervical pain among smokers. 